\title{
Letter to the editor: Surgical technique used in the UK for native tissue anterior pelvic organ prolapse repair (VaST)
}

\author{
Mallorie L. Hoover ${ }^{1}$ (ID $\cdot$ Annie S. Stachowicz ${ }^{1}$ Mickey M. Karram ${ }^{1}$ \\ Received: 27 October 2020 / Accepted: 16 November 2020 / Published online: 25 November 2020 \\ (C) The International Urogynecological Association 2020
}

\section{To the Editors:}

We read with interest the article, "Surgical technique used in the UK for native tissue anterior pelvic organ prolapse repair (VaST)," by Fairclough et al., published in Volume 31, Issue 8 of International Urogynecology Journal [1]. We agree that variation in surgical technique for pelvic organ prolapse repair undoubtedly exists and contributes to the difference in published versus real-life outcomes. Furthermore, we share the authors' convictions regarding the need for surgeons to follow evidence-based descriptions of surgical techniques to achieve optimal results. However, we write to highlight that the current literature speaks to the importance of concomitantly addressing the vaginal apex in cases of advanced anterior compartment prolapse.

A 2006 cross-sectional study comparing pelvic organ prolapse quantification (POPQ) findings of women with symptomatic pelvic organ prolapse found that anterior vaginal wall prolapse was highly correlated with apical prolapse. The authors found that apical prolapse (POPQ point $\mathrm{C}$ ) is highly correlated with anterior vaginal wall prolapse (POPQ point $\mathrm{Ba}$ ) with a strong correlation coefficient of $0.835(P<.001)$ [2]. Furthermore, up to $60 \%$ of the size of the size of cystoceles has been attributed to apical descent [3]. In a simulated study evaluating the role of apical vaginal support on anterior and posterior vaginal wall prolapse, Lowder et al. found that simulated apical support changed point Ba to stage 0 or 1 in $55 \%$ of cases [4].

Our preferred method for native tissue suspension of the vaginal vault either at the time of hysterectomy or in patients with post-hysterectomy vaginal vault prolapse is intraperitoneal colpopexy via uterosacral ligament suspension as it maintains the natural orientation of the vaginal access with good

Mallorie L. Hoover

mallorie.hoover@thechristhospital.com

1 Department of Female Pelvic Medicine and Reconstructive Surgery at The Chirst Hospital, 2123 Auburn Avenue, MOB Suite 307, Cincinnati, OH, USA long-term results. In cases without an enterocele or in which the enterocele cannot entered, we then utilize an anterior approach to sacrospinous ligament fixation.

Discussing the surgical technique for native tissue repair is critical in an era where the circumstances surrounding mesh use have shifted. We feel is it more important to highlight the need for concomitant apical procedures in cases of advanced anterior vaginal wall prolapse than to highlight variations in surgical technique of native tissue anterior repair. The authors conclude further studies are needed to evaluate the effectiveness of surgical anterior repair techniques, but we firmly believe this narrow scope of research misses the point: it truly is all about the apex.

We look forward to the authors' response to this letter.

\section{References}

1. Fairclough E, Segar J, Myers J, et al. Surgical technique used in the UK for native tissue anterior pelvic organ prolapse repair (VaST). Int Urogynecol J. 2020. https://doi.org/10.1007/s00192-019-04103-8.

2. Rooney K, Kenton K, Mueller ER, et al. Advanced anterior vaginal wall prolapse is highly correlated with apical prolapse. Am J Obstet Gynecol. 2006. https://doi.org/10.1016/j.ajog.2006.06.065.

3. DeLancey JOL. Surgery for cystocele III: Do all cystoceles involve apical descent?: Observations on cause and effect. Int Urogynecol J. 2012.

4. Lowder JL, Park AJ, Ellison R, et al. The role of apical vaginal support in the appearance of anterior and posterior vaginal prolapse. Obstet Gynecol. 2008. https://doi.org/10.1097/01.AOG. 0000297309.25091.a0.

Publisher's note Springer Nature remains neutral with regard to jurisdictional claims in published maps and institutional affiliations. 